\title{
TRADISI BEDAH BUMI DI JAWA DALAM PANDANGAN ISLAM
}

\author{
Khoirin Nurul Farichatin Nichlah, Ashif Az Zafi \\ Institut Agama Islam Negeri (IAIN) Kudus \\ Khoirin.cantik@gmail.com , Ashifazzafi@iainkudus.ac.id
}

\section{ABSTRACT}

Indonesia has many traditions that are still very thick, one of which is in Java. In Java has a unique tradition when after eater people died, namely earth surgery. This tradition aims to pray for the deceased as well as a form of sincerity of the family left behind. This paper aims to see the tradition of earth surgery in Java and Islamic views of the tradition. The aim is to find out the tradition before the funeral takes place, the tradition after the funeral takes place and to know the Islamic view of the tradition. The research method used in writing. This is a qualitative descriptive method and a literature method. Keywords: tradition, earth surgery, Islamic outlook.

Kata kunci: tradisi, bedah bumi, pandangan Islam.

\section{A. PENDAHULUAN}

Indonesia merupakan negara yang memiliki agama, suku, dan ras yang sangat beranekaragam. Bersamaan dengan hal itu Indonesia juga memiliki keanekaragaman budaya serta tradisi di setiap daerahnya. Tradisi sendiri memiliki makna sebagai sesuatu yang dilakukan sejak lama oleh suatu kelompok masyarakat atau perseorangan yang dilakukan secara terus-menerus dan diwariskan dari generasi ke generasi berikutnya baik berupa tulisan atau lisan agar tidak punah. ${ }^{1}$

\footnotetext{
1 Wawancara dengan bapak Andi Purwanto pada tanggal 22 Maret 2020
} 
Adat atau tradisi dalam islam disebut sebagai 'urf. Secara etimologi 'urf berarti sesuatu yang baik. Sedangkan secara terminologi berarti suatu perbuatan yang logis yang dilakukan oleh manusia secara terus menerus (continue). Dalam hal ini Abdul Wahab Khalaf menyatakan bahwa 'urf adalah sesuatu yang sudah dikenal manusia dan menjadi kebiasaan baik yang berkaitan dengan perbuatan, perkataan atau hal yang berkaitan dengan meninggalkan perbuatan tertentu. Dalam redaksi lain adat adalah segala sesuatu yang sudah dikenal dan menjadi kebiasaan yang berlaku dalam kehidupan manusia baik berupa perkataan ataupun perbuatan. ${ }^{2}$

Di Indonesia sendiri tradisi masih sangat kental di daerah daerahnya. Salah satunya di Pulau Jawa memiliki banyak tradisi dan adat istiadat yang sangat kental dengan ajaran nenek moyang. Setelah Islam datang ke Nusantara dan para walisongo mulai menyebarkan agama Islam di tanah Jawa sedikit demi sedikit nilai-nilai budayanya bersentuhan dan berakulturasi dengan agama Islam. Mereka saat menyebarkan agama islam tidaklah serta merta langsung menghapus dan menolak ajaran nenek moyang. Karena Islam datang bukan untuk menghapus sesuatu yang sudah ada sebelumnya, namun sesuatu yang sudah ada itu akan di ukur dengan ajaran Islam. ${ }^{3} \mathrm{Dan}$ hanya yang bertentangan dengan agama Islam yang ditolak dan dihapuskan sehingga islam dapat menjadi agama yang rahmatan lil 'alamin. Sebagai contoh pada masa walisongo yaitu Sunan Kalijaga melakukan dakwah tersebut dengan melalui kesenian seperti wayang kulit, tembang, grebek maulidin juga ritual pemakaman.

\section{B. PEMBAHASAN}

\section{Tradisi Prosesi Sebelum Pemakaman}

Saat ada warga yang meninggal biasanya para tetangga akan berbondong bondong datang dan membantu dan sekaligus menghibur keluarga yang ditinggalkan. Para wanita menyiapkan rangkaian bunga berbentuk lingkaran dengan jumlah ganjil dan panjang satu meter setengah tanpa melepas jarum dari benangnya dan sebagian lagi membantu memasak makanan untuk selamatan surtunah atau bedah bumi. Dan para laki laki menyiapkan peralatan pemakaman seperti keranda, payung, senti, serta liang lahat. ${ }^{4}$

2 Imam Musbikin, Qawaid Al-Fiqhiyyah, Jakarta: PT. Raja Grafindo, 2001

3 M. Tholhah Hasan, Islam Dalam Perspektif Sosio Kultural, Jakarta: Lantabora Press, 2005:hal.19

4 Nurul Hasanah, Nilai-nilai Pendidikan Islam Dalam Budaya Jawa (Telaah Prosesi Adat Pemakaman Pada mAsyarakat Pager Kec. Kaliwungu Kab. Semarang Tahun 2014), Skripsi, STAIN Salatiga, 2015 
Sebelum pemakaman kyai setempat atau modin melakukan pidato singkat sebagai wakil ashabul musibah yang berisi tentang permohonan maaf keluarga kepada warga sekitar apabila almarhum memiliki kesalahan mohon untuk lapang dada dan di maafkan segala kesalahan almarhum. Dan kyai setempat atau modin juga menanyakan kepada warga sekitar apakah almarhum memiliki masalah utang piutang yang belum lunas. Dan apakah dari yang bersangkutan ingin meminta agar hutang itu di lunasi atau kah di ikhlaskan,agar dibicarakan dengan keluarga yang ditinggalkan. Karena mayit tidak akan di makamkan selagi masih memiliki masalah utang piutang. Hal ini dilakukan karena walaupun terlihat sepele namun dapat menjadikan beban dan siksa kubur kepada mayit tersebut. Barulah saat masalah utang tersebut selesai jenazah dapat dimakamkan. Dan biasanya para pelayat laki laki ikit menghantarkan sampai liang lahat dan pelayat perempuan melakukan tahlilan di rumah duka.

Adab pemakaman di Jawa sama dengan yang pada umumnya yaitu memandikan, mengkafani, mensholati, dan menguburkan. ${ }^{5}$ Namun,ada satu adat sebelum mayit di berangkatkan ke pemakaman yaitu terdapat tradisi brobosan/ tlusupan. Dengan cara saat keranda sudah diangkat dan berada di depan rumah keluarga yang ditinggalkan secara bersamaan masuk ke kolong keranda dari arah kiri ke kanan. ${ }^{6}$ Hal ini di maksudkan sebagai simbol bahwa keluarga telah mengikhlaskan serta siap melepaskan kepergian almarhum ke pemakaman dan agar keluarga almarhum senantiasa mengingat almarhum. ${ }^{7}$

\section{Tradisi Setelah Pemakaman}

Setelah para pelayat kembali dari pemakaman dan para wanita selesai mengadakan tahlilan mereka tidak langsung pulang kerumah masing masing. Dikarenakan biasanya di daearah Jawa terdapat adat bedah bumi atau yang lebih di kenal sebagai Slametan surtunah. Slametan sendiri berasal dari kata selamat yang berarti berdoa untuk meminta keselamatan bagi mayit. Selamatan juga dapat dimaknai sebagai sesuatu yang dari kejadian kejadian yang tak di kehendaki. ${ }^{8}$

Selametan atau bedah bumi dalam kematian ini merupakan bentuk akti-

5 Nasrun Harun, Ushul Fiqh, Jakarta: Logos Wacana Ilmu, 1997:hal.137

6 Suwito S., Hidayat A., Agus S., Tradisi Dan Ritual Kematian Wong Islam Jawa, IBDA'Jurnal Kajian Islam Dan Budaya, Vol. 13 No. 2, 2015, hal. 210

7 Suwito....., Tradisi Dan Ritual Kematian Wong Islam Jawa......, hal. 211

8 Dinia Agustia Artika Sari, Selamatan Kematian Di Desa Jaweng Kabupaten Boyolali, Haluan Sastra Budaya, Vol. 1 No. 2, December 2017, hal 147- 166 
vitas sosial berwujud upacara Jawa penganut animisme serta merupakan bagian dari tradisi lokal yang memiliki latar belakang nilai tersendiri. ${ }^{9}$ Ketika Islam datang dan masuk ke tanah Jawa, para wali melakukan pendekatan dengan cara mengakulturasikan tradisi bedah bumi dengan doa doa dalam ajaran Islam, biasanya berupa acara pengajian ataupun tahlilan. ${ }^{10} \mathrm{Namun}$, tetap saja terdapat kelompok yang menganggap bahwa tradisi ini adalah bid'ah dan dosa tanpa memikirkan dampak positif dari tradisi ini. Oleh karena itu, terjadilah dialektika antara agama dan kebudayaan. Agama memberikan warna (spirit) terhadap kebudayaan, dan kebudayaan memberikan kekayaan terhadap agama. 11

Dalam Al Qur'an sendiri tidak dijelaskan tentang tradisi slametan ini. Namun, orang Jawa yakin jika do'a anak sholeh terhadap orang yang sudah meninggal tetap diterima. Dan setelah islam datang dimbuhi bacaan tahlil. Selametan ini biasanya dilakukan oleh pelayat pria dan sajiannya berupa tumpeng pungkur (nasi tumpeng yang di belah menjadi dua secara vertikal dan diletakkan saling membelakangi), ingkungan ayam, sayur urap (kuluban), serta lauk pauk(tahu,tempe,telur,teri). ${ }^{12}$ Nasi pungkur ini memiliki filosofi sebagai simbol penyempurnaan arwah mayit dan sebagai simbol keikhlasan keluarga atas kepergian almarhum. Dan ditaruh saling membelakangi memiliki makna bahwa perpisahan antara keluarga dan mayit,dan tidak dapat bertemu seperti biasa karena sudah berbeda alam. ${ }^{13}$

\section{3.. Nilai Nilai Kebudayaan yang Terkandung dalam Tradisi Bedah Bumi.}

Nilai dapat diartikan sebagai ukuran-ukuran, patokan-patokan, anggapananggapan yang hidup dan berkembang serta dianut oleh masyarakat untuk menentukan benar, pantas, luhur,dan baik dilakukan.

Berikut arti nilai menurut para ahli :

1) Menurut Anthoni Giddens, Nilai adalah gagasan-gagasan yang dimiliki oleh seseorang atau kelompok yang dikehendaki, layak, dan yang baik atau yang buruk.

9 Fachrir Rohman, Pernikahan di Nusa Tenggara Barat Antara Islam dan Tradisi, Mataram: LEPPIM IAIN Mataram, 2012

${ }^{10}$ Dinia Agustia Artika Sari, "Selamatan Kematian Di Desa Jaweng Kabupaten Boyolali....."

${ }^{11}$ Fachrir Rahman, "Pernikahan di Nusa Tenggara Barat Antara Islam dan Tradisi.........."

${ }^{12}$ Wawancara dengan Bapak Noor Ali Chusnin pada tanggal 29 Maret 2020.

${ }_{13}$ Wawancara dengan bapak Sumantri pada tanggal 21 Maret 2020 
2) Menurut Horto \& Hunt, Nilai adalah gagasan tentang apakah suatu tindakan itu penting atau tidak.

3) Menurut B. Simanjuntak merumuskan nilai sebagai ide-ide masyarakat tentang sesuatu yang baik.

4) Menurut Robert M. Z. Lawang, Nilai adalah gambaran mengenai apa yang diinginkan, pantas, berharga dan memengaruhi perilaku sosial orang-orang yang memiliki nilai tersebut.

5) Menurut Soerjono Soerkanto, nilai berlaku sebagai konsepsi abstrak dalam diri manusia mengenai apa yang dianggap baik atau buruk.

Dari uraian diatas dapat disimpulkan bahwa nilai adalah suatu kualitas atau penghargaan terhadap sesuatu yang menjadi dasar penentu tingkah laku, kualitas ataupun keadaan manusia baik lahir maupun batin.

\section{Pandangan Islam Mengenai Tradisi Bedah Bumi.}

Melihat pelaksanaan tradisi bedah bumi setelah pemakaman di tanah Jawa mengikuti adat istiadat nenek moyang dan sudah menjadi suatu keharusan, sehingga apabila tidak dilaksanaan masyarakat akan menganggap tidak menghormati para leluhur. ${ }^{14}$ Dalam tradisi bedah bumi ini memiliki 2 sisi,yaitu sisi positif dan sisi negatif. Sisi positifnya yaitu mengandung nilai agama yaitu pada saat acara bedah bumi dilaksanakan kirim doa dengan pembacaan yasin dan surah surah pendek.

Dalam suatu hadist disebutkan bahwa:

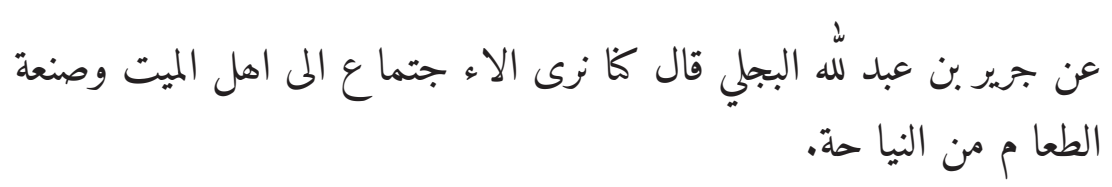

Artinya: Dari Jarir bin 'Abdillah Al- Bajalie, ia berkata 'Kami menganggap berkumpul-kumpul di (rumah) keluarga si mayit dan membuat makanan sesudah menguburkanya, merupakan bagian dari meratap. ${ }^{15}$

Perkataan "kami menganggap............" memiliki makna bahwa mereka berkumpul setelah pemakaman dan makan disana adalah sebuah bentuk dari meratap. Hal ini dilakukan sebagai usaha untuk meringankan beban keluarga

\footnotetext{
${ }^{14}$ Nurul Mahmudah dan Abdur Rahman Adi Saputera, Tradisi Ritual Kematian Islam Kejawen Ditinjau Dari Sosiologi Hukum Islam, Analisis: Jurnal Studi Keislaman, Vol.19 No. 1 Juni 2019, hal. 177-192.

15 Wawancara dengan bapak Sumantri pada tanggal 21 Maret 2020
} 
yang ditinggalkan dan suguhan makanan untuk mengenyangkan keluarga si mayit sampai malam.

Namun, penyuguhan makanan kepada penta’ziah masih diperselisihkan oleh para ulama dan terdapat 3 pendapat,yaitu :

Pertama, pendapat yang menyatakan makruh, diikuti oleh mayoritas ulama madzhab 4. Pendapat ini dikutip pada I'anah at - Thalibin oleh Syaikh al Bakhri yaitu :

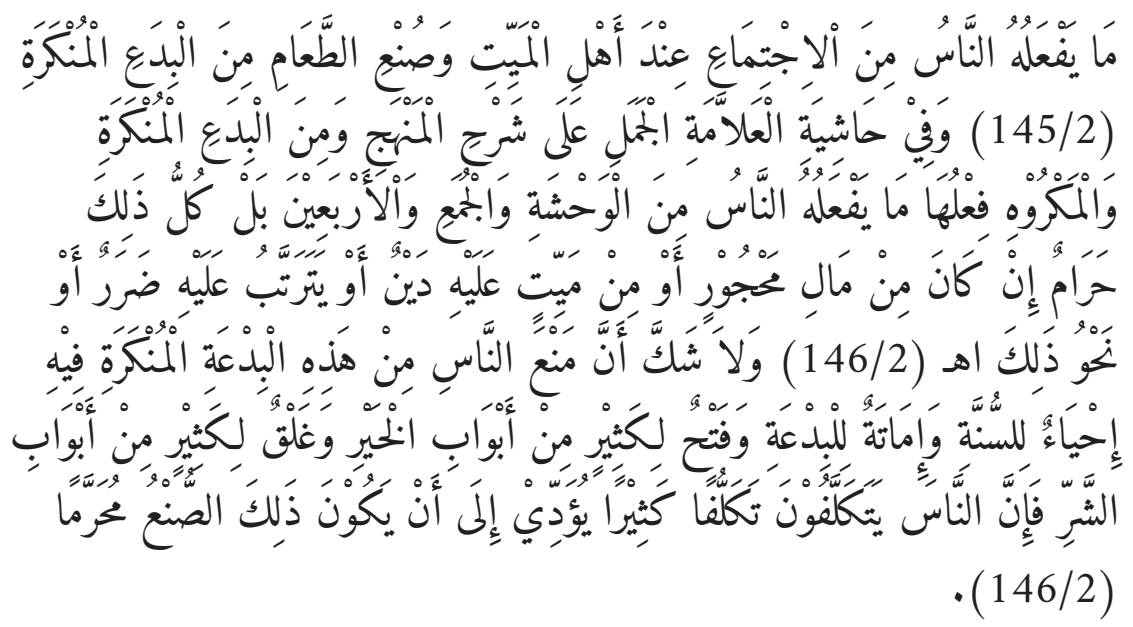

Artinya: "Apabila manusia melakukan perkumpulan dirumah duka dan menyediakan makanan itu termasuk bid'ah yang munkar. "Di antara bid'ah yang munkar adalah tradisi selamatan (kenduri) kematian yang disebut wahsyah, juma', dan arba'in (nama-nama tradisi di Hijaz). Bahkan semua itu dihukumi haram apabila makanan tersebut diambil dari harta mahjur 'alaih (orang yang belum dibolehkan mentasarufkan hartanya seperti anak yang belum dewasa), atau harta si mati yang memiliki hutang, atau dapat menimbulkan madarat pada si mati tersebut dan sesamanya. Tidak dapat diraguan lagi bahwa mencegah diri dari bid'ah yang munkar dapat menghidupkan sesuatu yang sunnah,membuka pintu-pintu kebaikan serta menutup pintu - pintu kejelekan. Karena seseorang yang memaksakan diri dapat membawanya pada hukum keharaman. ${ }^{16}$

Demikian fatwa dari Sayyid Ahmad Zaini Dahlan Asy - Syafi'i yang di kutip oleh Syaikh Al Bakhri dalam kitab I'anah At Thalibin.

Dari fatwa diatas dapat disimpulkan bahwa selamatan pada hari kematian hingga hari ke tujuh dan hari ke 40 adalah makruh, selagi hidangan yang disa-

${ }^{16}$ Syaikh al-Bakhri, juz 2 : hal. 145-146 
jikan berasal dari harta keluarga mayyit. Dan bukan berasal dari harta majhur 'alaih, harta mayyit yang masih memiliki hutang, serta yang dapat mendatangkan kemadharatan. Karena itu akan mengubah hukumnya, yang asalnya makruh menjadi haram.

Kedua, yaitu pendapat yang menyatakan mubah. Tradisi bedah bumi ini dapat dikatakan mubah jika makanan yang disajikan berasal dari bantuan para tetangga dan yang pada mulanya hukumnya makruh berubah menjadi tidak makruh. Seperti yang di ungkap dalam kitab Jawahir Al Fatawa yang berbunyi:

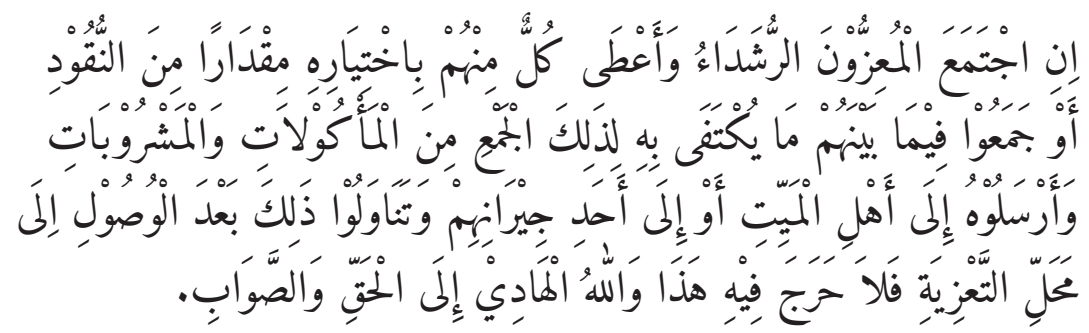

Artinya: "Apabila orang-orang yang berta'ziyah yang dewasa berkumpul, lalu masing-masing mereka menyerahkan sejumlah uang, atau mengumpulkan sesuatu yang mencukupi untuk konsumsi perkumpulan (selamatan kematian) berupa kebutuhan makanan dan minuman, dan mengirimkannya kepada keluarga si mati atau salah satu tetangganya, lalu mereka menjamahnya setelah sampai di tempat ta'ziyah itu, maka hal tersebut tidak mengandung hukum kesulitan (tidak apa-apa). Allah lah yang menunjukkan pada kebenaran. ${ }^{17}$

Pendapat ini pernah diriwayatkan dai Khalifah Umar, Sayyidatina Aisyah,dan Imam Malik bin Anas. Dan disebutkan pula oleh Al Hafidz Ibnu Hajar yang diriwayatkan oleh Khalifah Umar bin Khattab yang berbunyi:

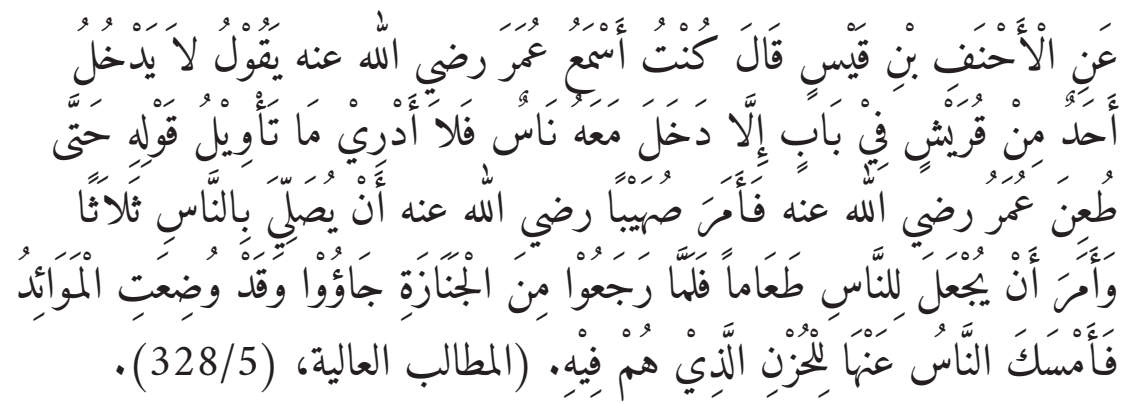

Artinya: "Dari Ahnaf berkata : aku mendengar Umar r.a. berkata "Seseorang dari kaum Quraisy tidak memasuki satu pintu, kecuali orang-orang akan masuk bersamanya."

${ }^{17}$ Syaikh Abdul Karim, Jawahir al Fatawa juz 1: hal. 178 
Pada saat itu aku tidak mengerti perkataannya, sampai Umar ditusuk dan meminta Shuhaib untuk menggantikannya sebagai imam sholat selama 3 hari serta memerintahkan untuk menyediakan makanan. Namun, saat Umar wafat dan mereka kembali dari pemakamannya makanan telah selesai dimasak untuk selanjutnya dihidangkan. Tetapi mereka tidak jadi karena duka yang masih menyelimutinya. ${ }^{18}$

Hal ini juga pernah dilakukan oleh sayyidah Aisyah, istri Rasulullah SAW. Imam Muslim meriwayatkan dari Shahihnya :

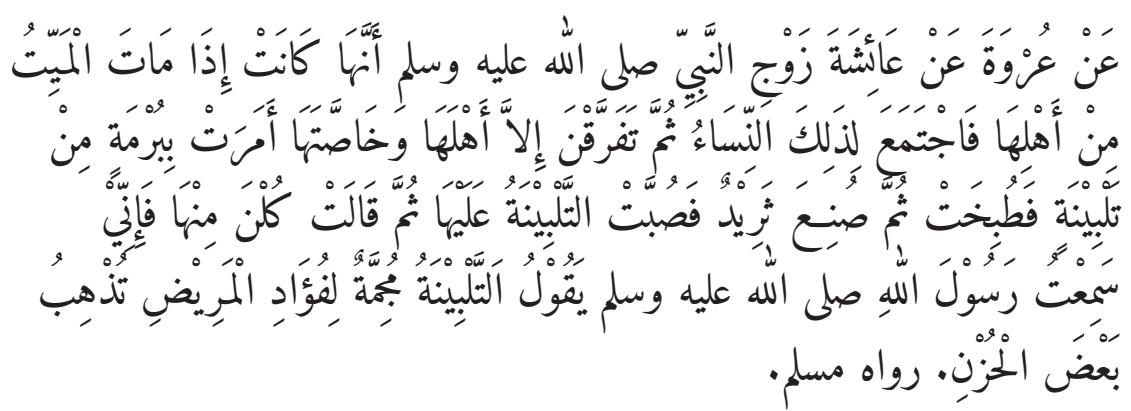

Artinya: "Dari Urwah, dari Aisyah Istri Nabi SAW bahwa apabila seseorang dari keluarga Aisyah meninggal, lalu para perempuan berkumpul untuk berta'ziah kemudian mereka berpisah kecuali keluarga dan kerabat dekat, maka Aisyah menyuruh dibuatkan talbinah seperiuk kecil, lalu dimasak. Kemudian dibuatkan bubur,dan talbinah itu di tuangkan kedalamnya. Lalu Aisyah berkata: "Makanlah kalian, karena Aku mendengar Rasulullah SAW bersabda: "Talbinah dapat menenangkan hati yang sakit dan menghilangkan sebagian kesusahan."

Begitu juga Imam Malik bin Anas,berpendapat bahwa tradisi bedah bumi ini hukumya jaiz(boleh).

Dalam hal ini, Syaikh Abdullah Al Jurdani berkata :

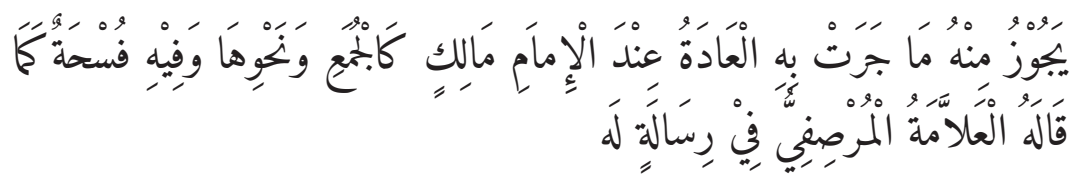

Artinya: "Hidangan kematian yang telah berlaku menjadi tradisi seperti tradisi Juma'dan sesamanya adalah boleh menurut Imam Malik. Pandangan

${ }^{18}$ Wawancara dengan bapak Sumantri pada tanggal 21 Maret 2020 
ini mengandung keringanan sebagaimana di katakan oleh Al Allamah Al Mursyid Al Anam dalam risalahnya."

Dari hadist diatas dapat disimpulkan bahwa pemberian makan setelah pemakaman kepada penta'ziah tidak haram.

Ketiga, pendapat yang mengatakan sunnah, telah diriwayatkan oleh kaum salaf sejak pada masa para sahabat.

Dalam kitab Az Zuhd,Iam Abu Ahmad bin Hambal meriwayatkan bahwa:

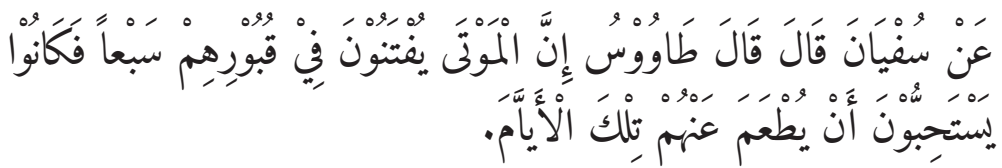

Artinya: "Dari Sufyan berkata: "Thawus berkata: "Sesungguhnya orang yang mati akan di uji dalam kubur selama 7 hari, oleh karena itu mereka menganjurkan bersedekah makanan selama hari hari itu." 19

Menurut Al Hafidz As Suyuti hadits di atas merupakan hadits mursal dengan sanad yang shahih. Hadits ini juga diperkuat oleh hadist Imam Mujtahid yang diriwayatkan oleh Ibnu Rajab dalam Ahwal al Qubur. Sehingga hadist Imam Thuwus ini dapat dihukumi sebagai hadits marfu' yang shahih.

Berdasarkan paparan diatas,dapat disimpulkan bahwa tradisi menghidangkan makanan (bedah bumi) kepada penta'ziah masih diperselisihkan oleh para ulama salaf antara makruh, mubah, dan sunnah. Tidak ada yang mengatakan bahwa tradisi itu haram, justru dianjurkan sejak zaman sahabat hingga abad ke - 10 H.Wallahu a'lam.

\section{SIMPULAN}

Di Indonesia masih kental akan tradisi daerahnya salah satunya di Jawa. Di Jawa sudah terjadi akulturasi budaya nenek moyang dengan agama Islam sejak masa walisongo, salah satunya tradisi pemakaman.

Seperti pertama sebelum dimakamkan terdapat tradisi brobosan/ tlusupan, yaitu anggota keluarga masuk ke kolong keranda dari arah kiri ke kanan dengan maksud sebagai simbol bahwa keluarga telah mengikhlaskan kepergian mayit serta agar keluarga yang ditinggalkan senantiasa mengingat almarhum.

Kedua, setelah pemakaman terdapat tradisi bedah bumi/slametan surtanah. Slametan ini disajikan beberapa makanan berupa tumpeng pungkur

\footnotetext{
${ }^{19}$ Imam Abu Ahmad bin Hambal, Mutiara Zubud, Jakarta: Pustaka Arofah.
} 
(nasi tumpeng yang di belah menjadi dua secara vertikal dan diletakkan saling membelakangi), ingkung ayam, sayur urap, lauk pauk. Nasi Pungkur ini memiliki filosofi sebagai simbol penyempurnaan arwah mayit dan sebagi simbol keikhlasan keluarga atas kepergian almarhum. Diposisikan saling membelakangi memiliki arti perpisahan antara keluarga dengan almarhum.

Para ulama mengenaijamuan setelah pemakaman ini terdapat 3 pandangan yaitu

1. Makruh, dalam hal ini diikuti oleh madzhab 4,seperti yang dikutip oleh Syaikh Al Bakhri dari fatwa gurunya Sayyid Ahmad Zaini Dahlan.

2. Mubah, jika makanan yang disajikan berasal dari bantuan para tetangga. Seperti yang dijelaskan dalam kitab Jawahir al Fatawa.

3. Sunnah, dalam hal ini sudah diriwayatkan oleh kaum salaf sejak masa para sahabat. Seperti yang di katakan oleh Imam Ahmad bin Hambal dalam Kitab Az-Zuhd. 


\section{DAFTAR PUSTAKA}

Damayanti, Tia. "Tradisi Brobosan dalam Upacara Kematian Masyarakat Jawa di kelurahan Rajabasa Raya Kecamatan Rajabasa Kota Bandar Lampung." Skripsi (Universitas Bandar Lampung), 2019.

Harun, Nasrun. Ushul Fiqh. Jakarta: Logos wacana Ilmu, 1997.

Hasan, M. Tholhah. Islam Dalam Perspektif Sosio Kultural. Jakarta: Lantabora Press, 2005.

Hasanah, Nurul. "Nilai-Nilai Pendidikan Islam Dalam Budaya Jawa (Telaah Prosesi Adat Pemakaman Pada Masyarakat Pager Kec. Kaliwungu Kab. Semarang Tahun 2014)." Skripsi (IAIN Salatiga), 2015.

Huda, M. Nurul. "Nilai Budaya Suku Jawa dalam Tradisi Ngijing Pasca Selametan Nyewu Prespektif Hukum Islam." Skripsi (IAIN Metro Lampung), 2019.

Karim, Syaikh Abdul. Jawahir al Fatawa juz 1. n.d.

Khalaf, Abdul Wahab. Ilmu Ushul Figh. Mesir: Dakwah Islamiyah Syahab Al Ashar, 1987.

Kusnawati. "Perspektif Hukum Islam terhadap Praktek Sedekah dalam Adat Kematian Sasak di Desa Karangbayan Kecamatan Lingsar." Mu'amalat: Jurnal kajian Hukum Ekonomi Syariah (IAIN mataram.) 7, no. 1 (Juni 2015).

Musbikin, Imam. Qawaid Al-Fiqhiyyah. Jakarta: PT. Raja Grafindo, 2001.

Rohman, Fachrir. Pernikahan di Nusa Tenggara Barat Antara Islam dan Tradisi. Mataram: LEPPIM Mataram, 2012.

Saputera, Nurul Mahmudah dan Abdur Rahman Adi. "Tradisi Ritual Kematian Islam Kejawen Ditinjau Dari Sosiologi Hukum Islam." Analisis: Jurnal Studi Keislaman 19, no. 1 (Juni 2019).

Sari, Dinia Agustia Artika. "Selamatan Kematian Di Desa Jaweng Kabupaten Boyolali." Haluan Sastra Budaya 1, no. 2 (December 2017).

Suwito S., Hidayat A., Agus S. "Tradisi Dan Ritual Kematian Wong Islam Jawa." IBDA' Jurnal Kajian Islam Dan Budaya 13, no. 2 (2015). 